\title{
Solution and Bulk Properties of Branched Polyvinyl Acetates
}

\section{Part I: Non-Newtonian Viscosity Behaviour}

\author{
L. M. HoBBs* and V. C. LoNG $\dagger$
}

\begin{abstract}
A series of linear and branched fractions of polyvinyl acetate of relatively narrow molecular weight distribution was prepared and characterized by solution viscosity, hydrolysis, and light scattering measurements. At a given molecular weight, the intrinsic viscosity of a branched fraction was less than that of a linear fraction. The viscosity loss which takes place after removal of branches, by hydrolysis followed by re-acetylation, is a sensitive indication of the presence of branching in polyvinyl acetate. However, the process is not quantitative because of the presence of nonhydrolysable branches in the branched polymer. Benzene solutions of linear and branched polymers above a molecular weight of about $2 \times 10^{6}$ were significantly non-Newtonian in character. The major factor contributing to the non-Newtonian behaviour was found to be molecular weight rather than structure. Therefore, even though the intrinsic viscosity of a high molecular weight fraction is dependent on shear rate, the ratio of the intrinsic viscosities of branched to linear fractions of the same molecular weight (a term used in the estimation of the degree of branching) is not sensitive to shear rate. Since the shear sensitivity or degree of non-Newtonian viscosity behaviour is dependent upon molecular weight, it is possible to detect the presence of branching in polymers of molecular weight greater than $2 \times 10^{6}$ by comparison of the shear sensitivities of branched and linear fractions of the same intrinsic viscosity.
\end{abstract}

THE work described in this paper and in parts of three further publications represents a continuation and extension of an earlier publication on the effect of branching on the viscosity of dilute solutions of polyvinyl acetate ${ }^{1}$.

In this, the first paper of the present series, the preparation, fractionation, and characterization of linear and randomly branched polymers of vinyl acetate will be described. The fractions were characterized by dilute solution viscosity, light scattering, and hydrolysis measurements. The effect of the rate of shear upon the viscosity of dilute solutions was also observed and will be discussed in terms of the molecular weight and structure of the fractions.

The synthesis of comb-shaped branched polymers of vinyl acetate by a grafting technique is described in the second paper $^{2}$. By that process branches of specified length and number were attached to backbone linear polymers of narrow molecular weight distribution.

A comparison of some dilute solution properties for fractions of linear, randomly branched, and the comb-shaped branched polymers is presented

*Present address: Bennettsville, South Carolina.

tPresent address: E. I. du Pont de Nemours and Co., Wilmington, Delaware. 
in the third paper'; and the effects of branching on the melt viscosity of polyvinyl acetate will be described in the fourth and final paper of this series ${ }^{4}$.

\section{E X P E R I M E N T A L}

The experimental procedures and techniques employed in this study have been described in detail ${ }^{1,5}$ and are reviewed below.

\section{Preparation of samples}

Polymerization-Five unfractionated polymers of vinyl acetate were utilized. Samples 1, 2 and 3 were described previously ${ }^{1}$. Samples 1, 2 and 5 were linear in structure and were prepared by similar techniques. Sample 5 was actually a combination of three batches formed at low conversion by photopolymerization at $-19^{\circ} \mathrm{C}$ with azo-bis-isobutyronitrile as the photosensitizer. The polymerization data are recorded in Table 1. Such con-

Table 1. Polymerization data for the three components of sample 5

\begin{tabular}{c|c|c|c|c}
\hline Sample No. & $\begin{array}{c}{[\eta]} \\
(d l / g)\end{array}$ & $\begin{array}{c}\% \\
\text { Conversion }\end{array}$ & $\begin{array}{c}\text { Yield } \\
(\mathrm{g})\end{array}$ & $\begin{array}{c}\text { Initiator* } \\
\text { concentration } \\
\left(\text { moles } / l . \times 10^{4}\right)\end{array}$ \\
\hline 5a & 2.91 & 4.0 & 38.3 & 2.38 \\
$5 \mathrm{~b}$ & 3.26 & 6.9 & 74.3 & 2.15 \\
$5 \mathrm{c}$ & 3.33 & 9.5 & 97.3 & 2.08 \\
\hline
\end{tabular}

*Ultra-violet source: $100 \mathrm{~W}$ mercury lamp at $30 \mathrm{~cm}$.

ditions are reported to yield essentially linear molecules ${ }^{6,7}$. The fact that the intrinsic viscosities of sample 5 and two of its fractions were not significantly reduced after hydrolysis and re-acetylation, as shown in Table 4, is strong support of the assumption that the material is linear in structure.

Samples 3 and 4 were of the commercial type, prepared by the suspension polymerization method to high conversion at a relatively high temperature. Both were highly branched and high in molecular weight but entirely soluble in benzene. Both samples were prepared by $\mathrm{Mr}$ Wellman of the Colton Chemical Company, Cleveland, Ohio, by a technique similar to that described by Schildknecht ${ }^{8}$. The substantial reduction of the intrinsic viscosities of sample 4 and several of its fractions after hydrolysis and reacetylation, as shown in Table 4, indicates that the material is highly branched. From the method of preparation it is considered that the branching is random in nature.

Fractionation-The samples were fractionated by the partial precipitation method using the solvent-non-solvent system of acetone- $n$-heptane ${ }^{1}$ at $35.0^{\circ} \pm 0.02^{\circ} \mathrm{C}$. The polymer concentration was $10 \mathrm{~g} / 1$. or less during the fractionations. After isolation, the fractions were dissolved in benzene and recovered by freeze drying. Most of the primary fractions were subjected to a second fractionation and some of these secondary fractions were subjected to an additional fractionation. A code used to designate the fractions consists of a series of digits: the first digit denotes the unfractionated sample, the second indicates the primary fraction in order of its isolation, 
and the third and fourth digits have similar significance for the secondary and tertiary fractions, respectively. The fractionation data for the fractions of samples 4 and 5 are listed in Tables 2 and 3.

Table 2. Viscosity data for the branched fractions of sample 4 in benzene at $35^{\circ} \mathrm{C}$

\begin{tabular}{|c|c|c|c|c|c|c|}
\hline Fraction & $\bar{M}_{w} \times 10^{-6}$ & $\begin{array}{c}{[\eta]} \\
(d l / g)\end{array}$ & $\begin{array}{c}\text { Slope } \\
b\end{array}$ & $k^{\prime}$ & $k^{\prime}+k^{\prime \prime}$ & $\begin{array}{c}\text { Yield } \\
(\mathrm{g})\end{array}$ \\
\hline 4 & & $3 \cdot 08_{0}$ & $3 \cdot 53$ & $0.37_{2}$ & 0.501 & \\
\hline $4-1-1-1$ & & $7 \cdot 15_{0}$ & $21 \cdot 78$ & $0.42_{6}$ & 0.500 & $2 \cdot 5$ \\
\hline $4-2-1$ & & $5 \cdot 84_{5}$ & $13 \cdot 20$ & $0.38_{5}^{6}$ & 0.501 & $3 \cdot 0$ \\
\hline $4-2-2$ & & $5 \cdot 68_{0}^{\circ}$ & $11 \cdot 71$ & $0.36_{3}^{3}$ & 0.500 & 6.0 \\
\hline $4-1-1-2$ & $12 \cdot 6$ & $4.82_{0}$ & 8.99 & $0.38_{7}^{3}$ & 0.502 & $2 \cdot 5$ \\
\hline 4-3-1 & & $4 \cdot 77_{0}$ & $8 \cdot 67$ & $0.38_{1}^{\prime}$ & 0.502 & $4 \cdot 3$ \\
\hline $4-3-2$ & $3 \cdot 76$ & $3 \cdot 79_{0}^{\circ}$ & $5 \cdot 10$ & $0.35_{5}$ & 0.501 & $5 \cdot 0$ \\
\hline $4-2-3$ & 6.43 & $3.50_{0}^{\circ}$ & $4 \cdot 73$ & $0.38_{6}$ & 0.502 & $6 \cdot 0$ \\
\hline $4-4-1$ & $2 \cdot 86$ & $2 \cdot 97_{0}^{\circ}$ & $3 \cdot 25$ & $0.36_{9}^{\circ}$ & 0.499 & $22 \cdot 5$ \\
\hline $4-4-2$ & $1 \cdot 64$ & $2 \cdot 26_{0}$ & $1 \cdot 76$ & $0.34_{s}^{9}$ & 0.498 & $9 \cdot 0$ \\
\hline $4-3-3$ & & $2 \cdot 23_{5}$ & $1 \cdot 85$ & $0.37_{0}$ & 0.502 & $3 \cdot 0$ \\
\hline $4-5-1$ & 1.43 & $1.96_{2}^{\circ}$ & $1 \cdot 35$ & $0.35_{1}^{0}$ & 0.499 & 3.5 \\
\hline $4-5-2$ & 0.730 & $1 \cdot 48_{5}$ & 0.800 & $0 \cdot 36_{3}$ & 0.501 & $9 \cdot 0$ \\
\hline $4-4-3$ & 0.731 & $1 \cdot 38_{5}^{\circ}$ & 0.673 & $0.35_{1}^{3}$ & 0.500 & $4 \cdot 8$ \\
\hline $4-5-3$ & 0.432 & $1 \cdot 10_{4}^{\circ}$ & 0.419 & $0.34_{4}$ & 0.500 & $10 \cdot 0$ \\
\hline $4-5-4$ & & $0.71_{6}$ & $0 \cdot 180$ & $0.35_{1}^{*}$ & 0.501 & $5 \cdot 2$ \\
\hline $4-6$ & & $0 \cdot 44_{5}$ & 0.055 & $0.27_{8}$ & 0.498 & $9 \cdot 3$ \\
\hline
\end{tabular}

\section{Hydrolysis and re-acetylation}

The procedures employed were similar to those described by Wheeler et al..$^{9}$ and the results are tabulated in Table 4 . Polymer was hydrolysed by treating a methanolic polymer solution $(0.75 \mathrm{~g} / \mathrm{dl})$ with ten parts of a five per cent solution of potassium hydroxide in methanol. The reaction mixture was held at $35^{\circ} \mathrm{C}$ for five to ten hours until the precipitation of polyvinyl alcohol was complete. The polyvinyl alcohol was separated, washed with methanol, and dried. The product was then re-acetylated by treatment with $40 \mathrm{ml}$ (per gramme of polymer) of a mixture of acetic anhydride, acetic acid, and pyridine (in proportion of $15: 5: 1$ ). The mixture was held at $100^{\circ} \mathrm{C}$ for one to two days or until the dissolution of the polyvinyl alcohol was complete. The reconstituted polyvinyl acetate was separated by pouring the reaction mixture into a large excess of water. The product was washed with water, dissolved in benzene, and recovered by the freeze-drying technique.

\section{Viscosity measurements}

The viscosity measurements were made with a modified Ubbelohde suspended level viscometer ${ }^{10}$. The capillary was $18.5 \mathrm{~cm}$ long, with an inside diameter of $0.0356 \mathrm{~cm}$. Flow measurements were made at $35.0^{\circ} \pm 0.02^{\circ} \mathrm{C}$ on benzene as solvent and at five solution concentrations so adjusted as to 
Table 3. Viscosity data for the linear fractions of sample 5 in benzene at $35^{\circ} \mathrm{C}$

\begin{tabular}{|c|c|c|c|c|c|c|}
\hline Fraction & $\bar{M}_{w} \times 10^{-6}$ & $\begin{array}{c}{[\eta]} \\
(d l / g)\end{array}$ & $\begin{array}{c}\text { Slope, } \\
b\end{array}$ & $k^{\prime}$ & $k^{\prime}+k^{\prime \prime}$ & $\begin{array}{c}\text { Yield } \\
(g)\end{array}$ \\
\hline 5 & \multirow{7}{*}{$3 \cdot 58$} & $3 \cdot 41_{0}$ & $4 \cdot 02$ & $0 \cdot 34_{6}$ & 0.499 & \\
\hline $5-2-2$ & & $5 \cdot 70_{5}$ & $11 \cdot 39$ & $0.35_{0}^{n}$ & 0.500 & $3 \cdot 7$ \\
\hline $5-2-1$ & & $5 \cdot 60_{3}$ & $10 \cdot 86$ & $0.34_{f}$ & 0.500 & $6 \cdot 6$ \\
\hline $5-1-1$ & & $5 \cdot 55_{n}$ & $10 \cdot 50$ & $0.34_{1}^{\prime \prime}$ & 0.500 & $4 \cdot 5$ \\
\hline $5-1-2$ & & $5 \cdot 54_{0}$ & 10.93 & $0 \cdot 35_{6}^{1}$ & 0.502 & 1.9 \\
\hline $5-1-3$ & & - & 一 & - & - & $2 \cdot 3$ \\
\hline $5-3-1$ & & $5 \cdot 25_{0}$ & $9 \cdot 56$ & $0.34_{7}$ & 0.500 & $4 \cdot 2$ \\
\hline $5-3-2$ & \multirow[t]{4}{*}{$2 \cdot 66$} & $4.97_{0}^{\circ}$ & $8 \cdot 69$ & $0.35_{2}^{7}$ & 0.500 & $5 \cdot 8$ \\
\hline $5-4-1$ & & $4 \cdot 57_{0}^{\circ}$ & $7 \cdot 20$ & $0 \cdot 34_{5}$ & 0.499 & $9 \cdot 0$ \\
\hline $5-2-3$ & & $4 \cdot 37_{2}$ & $6 \cdot 63$ & $0.34_{7}^{\circ}$ & 0.500 & $11 \cdot 2$ \\
\hline $5-2-4$ & & $-^{2}$ & - & - & - & $4 \cdot 8$ \\
\hline $5-4-2$ & \multirow[t]{6}{*}{$2 \cdot 28$} & $4 \cdot 29_{n}$ & $6 \cdot 46$ & 0.35 & 0.498 & $10 \cdot 2$ \\
\hline $5-3-3$ & & $4 \cdot 06_{0}$ & $5 \cdot 69$ & $0 \cdot 34_{5}$ & 0.499 & $11 \cdot 6$ \\
\hline $5-3-4$ & & - & - & - & - & $3 \cdot 3$ \\
\hline $5-5-1$ & & 3.95 & $5 \cdot 38$ & $0 \cdot 34_{5}$ & 0.499 & $6 \cdot 6$ \\
\hline $5-4-3$ & & $3 \cdot 76_{0}^{0}$ & 4.98 & $0.35_{2}^{5}$ & 0.501 & $4 \cdot 5$ \\
\hline $5-4-4$ & & - & - & ${ }^{2}$ & - & $6 \cdot 3$ \\
\hline $5-5-2$ & \multirow[t]{4}{*}{1.84} & $3 \cdot 71_{n}$ & $4 \cdot 80$ & $0.34_{g}$ & 0.500 & $10 \cdot 8$ \\
\hline $5-5-3$ & & $3 \cdot 32_{0}^{\prime \prime}$ & $3 \cdot 82$ & $0.34_{7}^{9}$ & 0.499 & $7 \cdot 7$ \\
\hline $5-5-4$ & & - & - & $-^{7}$ & - & $6 \cdot 3$ \\
\hline $5-6-1$ & & $2 \cdot 91_{5}$ & $2 \cdot 88$ & $0.33_{9}$ & 0.499 & $10 \cdot 2$ \\
\hline $5-6-2$ & $1 \cdot 14$ & $2 \cdot 81_{a}$ & $2 \cdot 77$ & $0.35_{0}^{9}$ & 0.499 & $9 \cdot 4$ \\
\hline $5-6-3$ & \multirow[t]{3}{*}{0.991} & $2 \cdot 50_{n}$ & $2 \cdot 13$ & $0 \cdot 34_{0}^{0}$ & 0.500 & $7 \cdot 4$ \\
\hline $5-6-4$ & & -" & - & - & - & $7 \cdot 9$ \\
\hline $5-7-1$ & & $1.966_{1}$ & $1 \cdot 30$ & $0.33_{9}$ & 0.499 & $5 \cdot 4$ \\
\hline $5-7-2$ & \multirow[t]{2}{*}{0.654} & $1 \cdot 77_{n}^{1}$ & 1.01 & $0.32_{2}$ & 0.498 & $6 \cdot 3$ \\
\hline $5-7-3$ & & $1.55_{7}$ & 0.810 & $0.33_{4}^{2}$ & 0.499 & $4 \cdot 0$ \\
\hline $5-7-4$ & \multirow[t]{2}{*}{0.438} & $1 \cdot 37_{2}^{\prime}$ & 0.629 & $0.33_{4}^{4}$ & 0.499 & $3 \cdot 5$ \\
\hline $5-7-5$ & & $-^{2}$ & - & $-^{4}$ & - & $9 \cdot 2$ \\
\hline
\end{tabular}

yield values of $\eta_{*}$ in the range of $1 \cdot 15$ to $1 \cdot 7$. Values of $[\eta], k^{\prime}$ and $k^{\prime \prime}$ were obtained from double plots ${ }^{11,12}$ according to the expressions:

and

$$
\eta_{s p} / c=[\eta]+k^{\prime}[\eta]^{2} c+\ldots
$$

$$
\frac{\ln \eta_{r}}{c}=[\eta]-k^{\prime \prime}[\eta]^{2} c+\ldots
$$

under the condition that $k^{\prime}+k^{\prime \prime}=0 \cdot 500 \pm 0 \cdot 002$, where the symbols have their usual significance. Values of intrinsic viscosity and Huggins $k^{\prime}$ are listed in Tables 2 and 3 for the fractions of series 4 and 5.

In addition to the viscosity measurements made under free fall conditions, the viscosities of selected linear and branched fractions were studied over a range of shear rates from about 500 to $5000 \mathrm{sec}^{-1}$. Shear rates above that at free fall (1 $920 \mathrm{sec}^{-1}$ for benzene) were obtained by applying air pressure to the top of the liquid in the capillary to increase the flow rate. Shear rates below that at free fall were obtained by applying air pressure to the bottom of the liquid in the capillary to retard flow. The results were carefully examined for evidence that application of air pressure at the 
bottom of the liquid in the capillary might sufficiently deform the suspended level to cause erroneous measurement. However, since plots of solvent flow time versus shear rate showed no abnormal behaviour or discontinuity, the technique was judged to be satisfactory for the purpose of this study.

The water manostat used to control the air pressure was similar to that described by Sharman et al..$^{13}$ with the addition of a constant-head water supply. Flow times were reproduceable to approximately \pm 0.2 per cent in the shear range indicated above. A kinetic energy correction of $20 / t$ was subtracted from all flow times, where $t$ is the flow time at free fall. Consideration of the Poiseuille equation shows that the kinetic energy correction is essentially independent of shear rate ${ }^{5}$.

The maximum rate of shear at the capillary wall was used in all correlations and was calculated by the following equation

$$
D=r g h d / 2 L \eta_{0} \eta_{r}
$$

where $r$ and $L$ are the radius and length of the capillary, respectively, $g$ is acceleration of gravity, $h$ is average effective height of the driving head and $d$ its density, $\eta_{0}$ is solvent viscosity, and $\eta_{r}$ is the relative viscosity of the solution. A more precise calculation for $D$ which accounts for nonNewtonian flow, suggested by van Oene and Cragg ${ }^{14}$, was not used because the correction was small under the conditions of this study and would not have significantly altered the correlations. For example, the correction for one of the most non-Newtonian cases, fraction 3-3, was only 1.5 per cent. Likewise, a similar correction to $\eta_{r}$ was omitted because the correction was small, about 1.5 per cent for fraction 3-3, compared to the observed changes in $\eta_{r}$.

\section{Light scattering measurements}

The light scattering measurements were made with a Brice-Phoenix light scattering photometer, model number 1410 , using a cylindrical type scattering cell with flat entrance and exit windows. The measurements were made with 4358 \& light, and methyl ethyl ketone was employed as the solvent, taking 0.080 as the value of $\mathrm{dn} / \mathrm{d} c^{15}$.

The scattering data were treated according to a method of $\mathrm{Zimm}^{16}$. Values of weight average molecular weight, $\bar{M}_{w}$, for selected samples are tabulated in Tables 2 and 3 . The values of the second virial coefficient and radius of gyration will be considered in the third paper of this series ${ }^{3}$.

\section{RESULTS AND DISCUSSION}

\section{Characterization of fractions}

Molecular weight and polydispersity-At a given molecular weight, the intrinsic viscosity of a branched fraction is lower than that of the linear polymer as shown in Figure 1. The weight average molecular weights of the linear fractions are related to the intrinsic viscosities in benzene at $35^{\circ} \mathrm{C}$ by the expression

$$
\log \bar{M}_{w}=5 \cdot 426+1 \cdot 48 \log [\eta]
$$

The above is typical behaviour for linear and branched materials. 
The polymer fractions are believed to be relatively narrow in molecular weight distribution because of the fractionation technique employed. This is particularly true of the secondary and tertiary fractions. It is realized; however, that the branched fractions must be somewhat more polydispersed because of the dependence of solubility on both molecular weight and structure.

An estimate of the degree of polydispersity was obtained for the linear fractions of series 5 from the shape of the reciprocal scattering curve of the light scattering data ${ }^{17}$. The ratio of $\bar{M}_{w} / \bar{M}_{n}$ averaged about $1 \cdot 1$ for these fractions. Although this method for estimating polydispersity is not applicable to branched polymers, the shape of the scattering envelopes of the branched fractions supports the contention that they are reasonably narrow fractions.

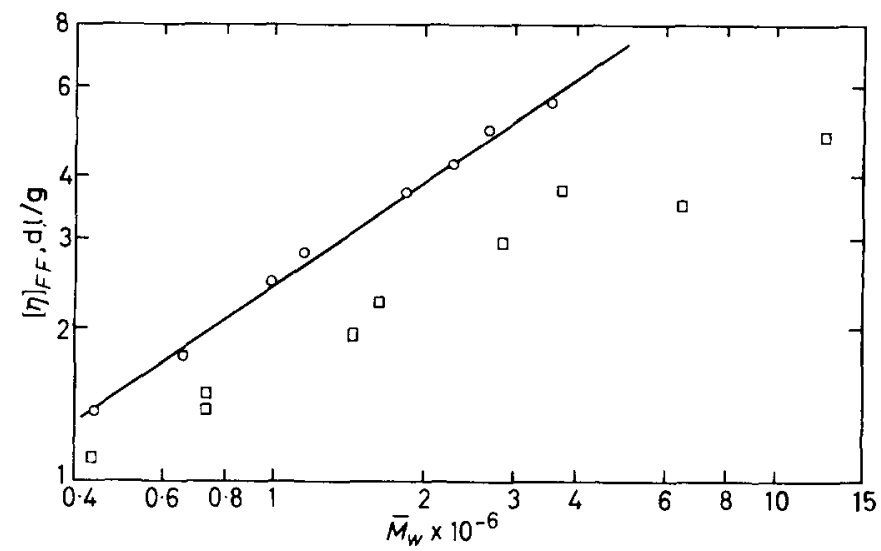

Figure 1 -Intrinsic viscosity in benzene at $35^{\circ} \mathrm{C}$ versus weight average molecular weight: $\square$-branched fractions, series 4; O-linear fractions, series 5

Identification of structure by hydrolysis and re-acetylation-Branching in polyvinyl acetate that results from chain transfer mechanisms may be classified as two types. Branches attached to the backbone chain via acetate groups are of the hydrolysable type, and branches connected directly to the backbone by $\mathrm{C}-\mathrm{C}$ bonds are non-hydrolysable. Both types of branching may be minimized by polymerization at low temperature and low conversion.

The decrease in intrinsic viscosity and molecular weight of the branched fractions of sample 4, Table 4, is a sensitive indication of the presence of hydrolysable branches, even for the lower molecular weight fractions which contain relatively few branches. The absence of a change in intrinsic viscosity of the linear polymer, sample 5, Table 4, establishes the absence of hydrolysable branches. Since the linear polymer was prepared at low temperature $\left(-19^{\circ} \mathrm{C}\right)$ and low conversion $(4-10$ per cent) it is assumed that the material also contains no non-hydrolysable branches and is, indeed, truly linear in structure.

The presence of non-hydrolysable branches in the branched material becomes apparent when the molecular weight of the hydrolysed and re- 
acetylated product calculated from $[\eta]_{H}$ by equation (4) is compared to the molecular weight of the same product from light scattering for fractions 4-4-2 and 4-1-1-1, Table 4. The fact that the measured molecular weight is greater than the calculated value is taken as evidence of non-hydrolysable

Table 4. Hydrolysis data $^{a, b}$

\begin{tabular}{c|c|c|c|c}
\hline Fraction & {$[\eta]$} & {$[\eta]_{H}$} & $\left(\bar{M}_{w}\right) \times 10^{-6}$ & $\left(\bar{M}_{w}\right)_{H} \times 10^{-6}$ \\
\hline 4 & 3.08 & 1.15 & - & 0.328 \\
$4-1-1-1$ & 7.15 & 1.34 & - & $0.412^{\circ}$ \\
$4-2-1$ & 5.85 & 1.39 & - & 0.435 \\
$4-4-2$ & 2.26 & 1.17 & 1.64 & $0.336^{d}$ \\
$4-5-1$ & 1.96 & 1.03 & 1.43 & 0.278 \\
$4-4-3$ & 1.39 & 0.89 & 0.731 & 0.224 \\
$4-5-2$ & 1.49 & 0.95 & 0.730 & 0.247 \\
$4-5-3$ & 1.10 & 0.85 & 0.432 & 0.210 \\
5 & 3.41 & 3.38 & - & - \\
$5-3-2$ & 4.97 & 5.03 & - & - \\
$5-6-2$ & 2.81 & 2.82 & - & - \\
\hline
\end{tabular}

a $H$ denotes properties after hydrolysis and re-acetylation.

b $\quad \bar{M}_{w}{ }^{{ }}{ }_{H}$ was calculated from $[\eta]_{H}$ by equation (4).

$c \quad\left(\bar{M}_{w}\right)_{H} \times 10^{-6}=0.674$ by light scattering.

d $\left(\bar{M}_{w}\right)_{H} \times 10^{-6}=0.408$ by light scattering.

branching. Thus, while the hydrolysis technique is a sensitive means of detecting hydrolysable linkages, it cannot be used as a quantitative means of estimating the degree of branching present in branched polyvinyl acetate.

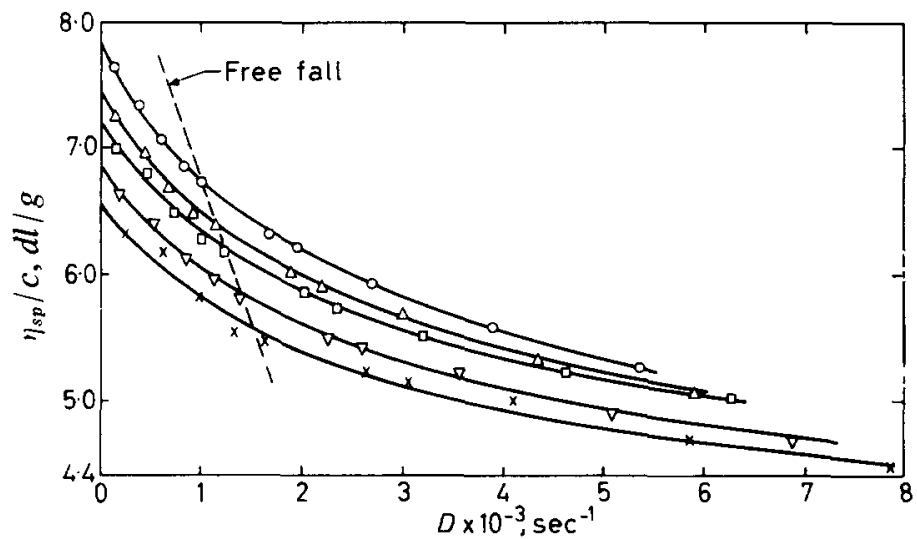

Figure 2-Reduced specific viscosity in benzene at $35^{\circ} \mathrm{C}$ versus rate of shear for fraction 3-3. Concentration $(\mathrm{g} / \mathrm{dl})$ : $O-0 \cdot 1280$, $\triangle-0 \cdot 1024, \square-0.0853, \nabla-0 \cdot 0640, \times-0.0320$

Non-Newtonian viscosity behaviour of dilute solutions

In studying the high molecular weight fractions, it was of interest to determine for the polyvinyl acetate-benzene system whether non-Newtonian behaviour affects the values of $[\eta]$ and $k^{\prime}$ of the Huggins equation as they are normally measured in a capillary viscometer and whether it affects the ratio of the intrinsic viscosities of branched and linear polymers, $[\eta]_{B} /[\eta]_{L}$, 
of a given molecular weight, a function that is utilized in estimating the degree of branching in Part $\mathrm{III}^{3}$ of this series of papers. Furthermore, it was desired to examine the effects of changes in shear rate upon the viscosities of linear and branched fractions as a possible means for detecting the presence of branched structures.

The viscosities of dilute solutions of selected linear and branched fractions were measured over a range of shear rates of approximately 500 to 5000 $\mathrm{sec}^{-1}$. A typical graph of the reduced specific viscosity, $\eta_{s p} / c$, versus shear rate, $D$, is shown in Figure 2. The curvature of the lines is due to the nonNewtonian character of the solutions. This curvature is large for polyvinyl acetate fractions of high molecular weight and, for a given fraction, it is somewhat greater at the higher concentrations. The straight line drawn across the curves represents the shear rates for the normal measurement at free fall, that is, at the shear rates produced in the particular viscometer with the particular solutions by gravity. Under free fall conditions, the more concentrated or more viscous solutions are subjected to relatively lower shear rates. This situation, as has been pointed out by Conrad et al. ${ }^{18}$, causes an increase in the slope of the $\eta_{s p} / c$ versus $c$ plot and thus results in an increased value of $k^{\prime}$.

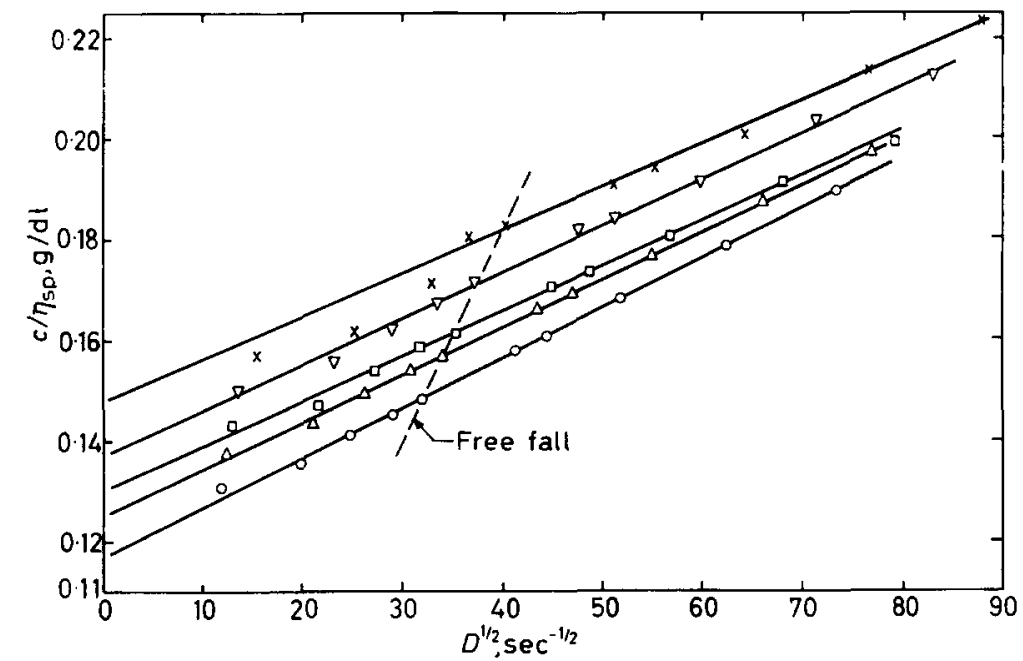

Figure 3-Reciprocal reduced specific viscosity in benzene at $35^{\circ} \mathrm{C}$ versus square root of shear rate for fraction 3-3. Concentration $(\mathrm{g} / \mathrm{d} 1): \mathrm{O}-0 \cdot 1280$, $\Delta \longrightarrow 0.1024, \square-0.0853, \nabla-0.0640, \times-0.0320$

In order to establish a reference point, Dr L. H. Cragg suggested the plot, $c^{\prime} \eta_{s p}$ versus $D^{1 / 2}$, Figure 3, which provides a means of extrapolation to the hypothetical condition of zero shear rate. The slopes of the lines for the several concentrations, $J_{c}$, are measures of the shear sensitivity of the solutions or the degree of their non-Newtonian character. The lines are represented by the equation

$$
\left(\eta_{s p} / c\right)_{c, D=0}^{-1}=\left(\eta_{s p} / c\right)_{c, D}^{-1}-J_{c} D^{1 / 2}
$$

For the low concentrations employed, it was found that $J_{c}$ is a linear function 
of concentration (graph not shown). Extrapolated values of $J_{c=\mathrm{c}}$ are listed in Table 5. It was also observed that a plot of the shear rates at free fall condition versus concentration yielded a straight line from which the shear rate at infinite dilution under free fall was found to be $1920 \mathrm{sec}^{-1}$, or the value calculated for the solvent. With this information, equation 5 at zero concentration becomes

$$
[\eta]_{D=0}^{-1}=[\eta]_{D=1920}^{-1}-1920^{-1 / 2} J_{c=0}
$$

where $[\eta]_{D=1920}$ is the intrinsic viscosity determined at infinite dilution and as the shear rate approaches that of pure solvent, i.e. the usual free fall intrinsic viscosity. Thus equation (6) provides the means for estimating the intrinsic viscosity at zero shear rate from the values of the intrinsic viscosity, $[\eta]_{F F}$, as normally measured under free fall conditions. The calculated values of $[\eta]_{D=0}$, recorded in Table 5, are useful as points of reference in comparing

Figure 4-Shear rate sensitivity versus weight average molecular weight: - -linear fractions, series 1 and 2; $\Delta$-branched fractions, series 3 ; 口branched fractions, series 4

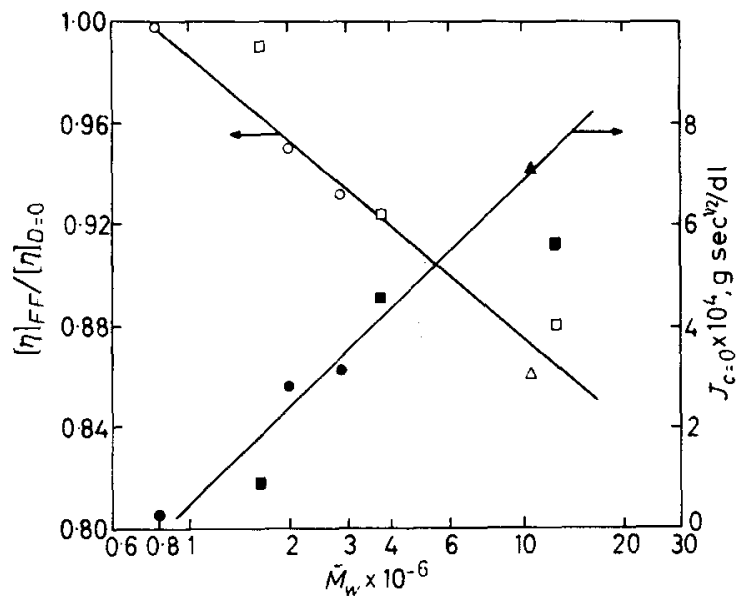

the effects of rate of shear encountered in routine measurements upon the viscosity properties of the linear and branched fractions. It is not suggested that they would be identical with results obtained by measurements at very low shear rates.

As noted in connection with Figure 2, the non-Newtonian character of the solutions of the high molecular weight fractions causes a marked reduction in the intrinsic viscosity and a moderate increase in $k^{\prime}$. The degree of non-Newtonian character or shear sensitivity is reflected in $J_{c=0}$ and the ratio $[\eta]_{F F} /[\eta]_{D=0}$. These variables are plotted against $\vec{M}_{w}$ in Figure 4 . It is evident that the shear sensitivity varies directly with $\bar{M}_{w}$ regardless of the presence of branching. Based on this information, the percentage change of $[\eta]_{F F}$ with respect to $[\eta]_{n=0}$ can be calculated. A 5 per cent decrease in the value of $[\eta]_{F F}$ occurs at a $\bar{M}_{w}$ of $2 \times 10^{6}$.

In Figure 5, the plot of the shear sensitivity function, $J_{c=0}$, versus Huggins $k^{\prime}$ shows the existence of a direct relationship between the two variables which, again, is insensitive to the presence of branching. Since $J_{c=0}$ is a direct function of molecular weight (Figure 4) it must be concluded that 
L. M. HOBBS and V. C. LONG

Table 5. Shear dependence data

\begin{tabular}{|c|c|c|c|c|c|c|}
\hline Fraction & $\begin{array}{r}{[\eta]_{D=0}} \\
(d l / g)\end{array}$ & $\begin{array}{l}{[\eta]_{F F}} \\
(d l / g)\end{array}$ & $k^{\prime}$ & $\bar{M}_{m} \times 10^{-6}$ & $J_{c} \times 10^{4}$ & $\begin{array}{c}\text { Concentra } \\
\text { tion } \\
(\mathrm{g} / \mathrm{dl})\end{array}$ \\
\hline $4-1-1-1$ & $10 \cdot 3$ & $7 \cdot 15$ & $0.42_{6}$ & - & $\begin{array}{c}9 \cdot 80 \\
10 \cdot 1 \\
10 \cdot 0 \\
10 \cdot 4\end{array}$ & $\begin{array}{c}0 \\
0.0248 \\
0.0372 \\
0.0740\end{array}$ \\
\hline $3-3$ & 6.61 & $5 \cdot 32$ & $0.42_{2}$ & - & $\begin{array}{l}8 \cdot 35 \\
8 \cdot 70 \\
9 \cdot 00 \\
9 \cdot 22 \\
9 \cdot 47 \\
9 \cdot 72\end{array}$ & $\begin{array}{c}0 \\
0.0320 \\
0.0640 \\
0.0853 \\
0 \cdot 1024 \\
0.1280\end{array}$ \\
\hline $4-1-1-2$ & $5 \cdot 47$ & $4 \cdot 82$ & 0.38 & $12 \cdot 6$ & $\begin{array}{l}5 \cdot 64 \\
6 \cdot 16 \\
6 \cdot 70\end{array}$ & $\begin{array}{c}0 \\
0.0561 \\
0.1121\end{array}$ \\
\hline $3-4$ & $5 \cdot 19$ & 4.47 & $0 \cdot 39_{8}$ & $10 \cdot 8$ & $\begin{array}{l}7 \cdot 10 \\
7 \cdot 90 \\
7 \cdot 76 \\
8 \cdot 12 \\
8 \cdot 28 \\
8 \cdot 84 \\
9 \cdot 18\end{array}$ & $\begin{array}{c}0 \\
0.0362 \\
0.0482 \\
0.0724 \\
0.0965 \\
0.1158 \\
0.1447\end{array}$ \\
\hline $3-5$ & $4: 35$ & 3.89 & $0 \cdot 38_{5}$ & - & $\begin{array}{l}6 \cdot 20 \\
6 \cdot 75 \\
6 \cdot 92 \\
7 \cdot 40\end{array}$ & $\begin{array}{c}0 \\
0.0624 \\
0.0936 \\
0.1871\end{array}$ \\
\hline $4-3-2$ & $4 \cdot 10$ & 3.79 & $0.35_{5}$ & $3 \cdot 76$ & $\begin{array}{l}4 \cdot 55 \\
5 \cdot 10 \\
5 \cdot 30 \\
6 \cdot 10\end{array}$ & $\begin{array}{c}0 \\
0.0510 \\
0.0765 \\
0.1530\end{array}$ \\
\hline $4-4-2$ & $2 \cdot 28$ & $2 \cdot 26$ & $0.34_{5}$ & 1.64 & $\begin{array}{l}0.9 \\
0.96\end{array}$ & $\begin{array}{c}0 \\
0 \cdot 2451\end{array}$ \\
\hline $2-1-1$ & $5 \cdot 31$ & 4.95 & $0.35_{2}$ & $2 \cdot 85$ & $\begin{array}{l}3 \cdot 13 \\
3 \cdot 22 \\
3 \cdot 30\end{array}$ & $\begin{array}{c}0 \\
0.0583 \\
0.1165\end{array}$ \\
\hline $2-4$ & $4 \cdot 10$ & 3.90 & $0.33_{0}$ & $2 \cdot 00$ & $\begin{array}{l}2 \cdot 80 \\
2 \cdot 80 \\
2 \cdot 93 \\
2 \cdot 97\end{array}$ & $\begin{array}{c}0 \\
0.0602 \\
0.0904 \\
0.1807\end{array}$ \\
\hline $1-2$ & $2 \cdot 10$ & $2 \cdot 09$ & 0.32 & 0.795 & $\begin{array}{l}0.3 \\
0.4 \\
0.5\end{array}$ & $\begin{array}{c}0 \\
0 \cdot 1963 \\
0 \cdot 2945\end{array}$ \\
\hline
\end{tabular}


molecular weight makes a significant contribution to the observed value of $k^{\prime}$. A gradual increase in $k^{\prime}$ with increasing molecular weight is seen in Figure 6. However, a few values of $k^{\prime}$ do lie substantially above the band

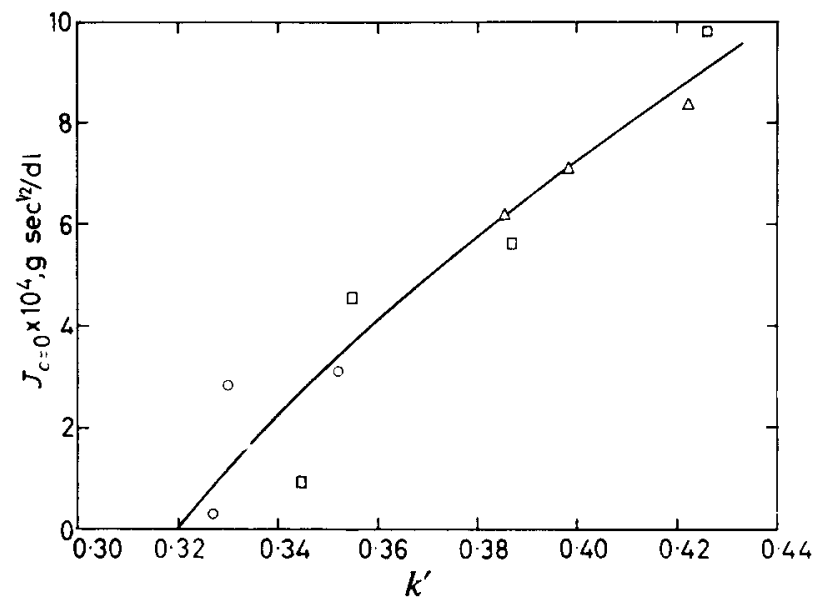

Figure 5-Shear rate sensitivity versus Huggins $k^{\prime}$ : linear fractions, series 1 and $2 ; \Delta$-branched fractions, series $3 ; \square-$ branched fractions, series 4

of points in Figure 6 , and it may be that $k^{\prime}$ is increased by certain types of molecular structure in branched polyvinyl acetate, as well as by molecular weight or non-Newtonian behaviour.

The ratio $[\eta]_{B} /[\eta]_{L}$ at a given molecular weight is useful in estimating the degree of branching, for example, by the method of Stockmayer and Fixman $^{19}$. While the individual values of $[\eta]_{B}$ and $[\eta]_{L}$ may be reduced by measurement at shear rates other than that of zero, the ratio is little changed,

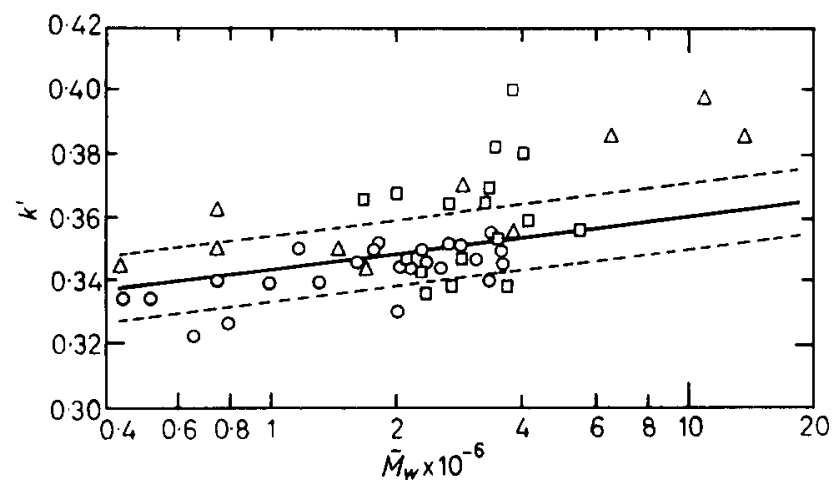

Figure 6-Huggins $k^{\prime}$ versus weight average molecular weight: $\bigcirc$-linear fractions, $\triangle$-randomly branched fractions, $\square-$ comb-shaped branched fractions

at least for the polyvinyl acetate-benzene system of this study. This results because of the strong dependence of shear sensitivity on molecular weight as shown in Figure 4 . Thus, the ratio $[\eta]_{B} /[\eta]_{L}$, as normally determined from measurements made under free fall conditions, will be useful for the 
estimation of the degree of branching for both Newtonian and nonNewtonian solutions.

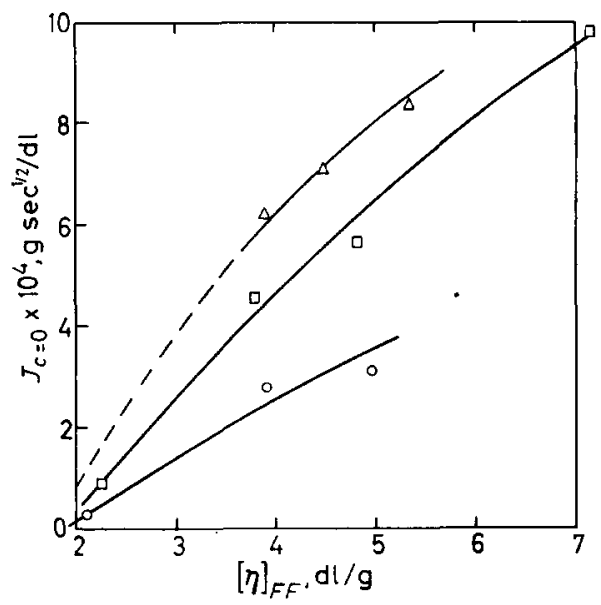

Figure 7-Shear rate sensitivity versus intrinsic viscosity in benzene at $35^{\circ} \mathrm{C}$ : $\mathrm{O}$-linear fractions, series 1 and 2; $\triangle$-branched fractions, series $3 ; \square$-branched fractions, series 4

In Figure 7 it may be seen that the shear sensitivity of the branched fractions increases more rapidly with $[\eta]$ than does that of the linear fractions. This is a consequence of the fact that the molecular weight of the branched fractions changes more rapidly with $[\eta]$. It would be possible, although tedious, to detect branching in polyvinyl acetate from viscosity data obtained over a range of shear rates without supplementary information regarding molecular weight. If $J_{c=0}$ for the sample of unknown structure were obtained and the $J_{c=0}$ versus [ $\left.\eta\right]$ curve of Figure 7 were established for linear fractions, then the ratio of $J_{c=0}$ for the unknown to $J_{c=0}$ of the linear polymer having the same value of $[\eta]$ could be obtained. Values of the ratio greater than unity would indicate the presence of branching.

We express our appreciation to the Goodyear Tire and Rubber Company for their contribution to the Michigan Memorial-Phoenix Project which has made this work possible. We also wish to thank Professor L. H. Cragg, of the University of Alberta, and Dr J. A. Manson, of the Air Reduction Company, for helpful suggestions, and $\mathrm{Dr} C$. H. Lu and Mr M. M. Gurvitch for their aid with portions of the experimental work while students at the University of Michigan.

\section{Department of Chemical Engineering and}

Michigan Memorial-Phoenix Project,

University of Michigan, Ann Arbor, Michigan

(Received December 1962)

\section{R E F E R E N C E S}

${ }^{1}$ Hobrs, L. M., Kothari, S. C., Long, V. C. and Sutaria, G. C. J. Polym. Sci. 1956, 22, 123

2 Berry, G. C. and Craig, R. G. Polymer, Lond. In press

${ }^{3}$ Berry, G. C., Hobrs, L. M. and Long, V. C. Polymer, Lond. In press 
4 Berry, G. C., Hobrs, L. M. and Long, V. C. Polymer, Lond. In press

${ }^{5}$ Long, V. C. Ph.D. Thesis, University of Michigan, 1958

- Burnetr, G. M., George, M. H. and Melville, H. W. J. Polym. Sci. 1955, 16, 31

${ }^{7}$ Matsumoto, M. and Ohyanagi, Y. J. Polym. Sci. 1960, 46, 520

${ }^{8}$ SCHILdKNeCHT, C. E. Vinyl and Related Polymers, pp 244-246. Wiley: New York, 1952

${ }^{9}$ Wheeler, O. L., ERNST, S. L. and Crozler, R. N. J. Polym. Sci. 1952, 8, 409

${ }^{10}$ Craig, A. W. and Henderson, D. A. J. Polym. Sci. 1956, 19, 215

11 Heller, W. J. Colloid Sci. 1954, 9, 547

12 Ewart, R. H. Advanc. Colloid Sci. 1946, 2, 211

${ }^{13}$ Sharman, L. J., Sones, R. H. and Cragg, L. H. J. appl. Phys. 1953, 24, 703

14 van Oene, H. and Cragg, L. H. J. Polym. Sci. 1962, 57, 209

${ }^{15}$ SchultZ, A. R. J. Amer. chem. Soc. 1954, 76, 3422

${ }^{16}$ ZIMM, B. H. J. phys. Colloid Chem. 1948, 52, 260; J. chem. Phys. 1948, 16, 1093, 1099

${ }^{17}$ Benort, H., Holtzer, A. M. and Doty, P. J. phys. Chem. 1954, 58, 635

${ }_{18}$ Conrad, C. M., TrIPP, V. W. and Mares, T. J. phys. Colloid Chem. 1951, 55, 1474

${ }^{19}$ Stockmayer, W. H. and Fixman, M. Ann. N. Y. Acad. Sci. 1953, 57, 334 